\title{
Metal Mountable Ladder Feed Line UHF-RFID Tag Antenna
}

\author{
Najwa Mohd Faudzi, Mohd Tarmizi Ali, Ismarani Ismail, Hadi Jumaat, Nur Hidayah Mohd Sukaimi \\ Antenna Research Group (ARG), Faculty of Electrical Engineering (FKE), \\ Universiti Teknologi Mara (UiTM), Shah Alam, Selangor, Malaysia
}

\begin{tabular}{l}
\hline \hline Article Info \\
\hline Article history: \\
Received Mar 16, 2015 \\
Revised Apr 20, 2015 \\
Accepted May 15, 2015
\end{tabular}

Keyword:

meander

Metal

microstrip patch

RFID

Tag antenna

T-match

\section{Corresponding Author:}

Najwa Mohd Faudzi,

Antenna Research Group (ARG), Faculty of Electrical Engineering (FKE),

Universiti Teknologi Mara (UiTM), Shah Alam, Selangor, Malaysia.

Email: najwa_nmf@yahoo.com

\begin{abstract}
A microstrip dipole UHF-RFID tag antenna that can be mounted on metal object is presented in this paper. The antenna, which has a very simple structure without any shorting pin and shorting plate, is composed of ladder feed line, rectangular loop, capacitive tip-loading and T-match structure. The insertion of ground plane in the tag antenna design reduces the negative impact of metal object to the performance of the tag antenna. The tag is designed to operate in the Malaysia frequency range with the center frequency of $921 \mathrm{MHz}$. The performance of the tag is evaluated through simulation and measurement in terms of impedance matching, antenna reflection coefficient and tag reading range. The measured reading range obtained when the tag is in free air and on metal object is $2.3 \mathrm{~m}$ and $2.2 \mathrm{~m}$ respectively.
\end{abstract}

Copyright (C) 2015 Institute of Advanced Engineering and Science. All rights reserved.

\section{INTRODUCTION}

In recent years, Radio Frequency Identification (RFID) technology is highly demanded in various applications; including animal tagging, object tracking, inventory process and also item-level-tagging. Therefore, rapid development in the RFID technology is required. The operating frequency of UHF-RFID system is between $860-960 \mathrm{MHz}$ with some variance in frequency from region to region depending on the radio regulation of that region [1]. The component that plays a vital role in the RFID system is RFID tag which is composed of an antenna and a chip. In designing the RFID tag, the size of the antenna and the sensitivity of the tag to the object it is attached to need to be considered [2] [3]. The tag will be mounted on the objects with different kind of materials including metal. However, metal object will strongly affect the performance of the tag due to the significant changes in the antenna impedance when it is attached on metal object [4].

According to image theory concept, if a dipole tag antenna is placed in close proximity to the metal surface, an identical mirror image antenna is formed due to the reflection from the metal surface, but the current flow is in reverse direction. Consequently, the electromagnetic fields produced by those antennas will cancel each other and lead to the reduction of radiating resistance [5]. Previous researchers have proposed several techniques to overcome this problem, which includes inserting a foam spacer between the antenna and the metal object with and also by using metamaterials for example Electromagnetic Band Gap (EBG) and Artificial Magnetic Conductor (AMC) [6] [7]. By using these techniques, the interference from the metallic surface can be reduced, but the size of the antenna will be increased and the antenna becomes more bulky. Printed inverted-F antenna (PIFA) is also commonly used for metal object tagging, but the fabrication cost of the PIFA is much higher due to the existence of shorting plate or shorting pin in the antenna design structure [8]. 
In this paper, a microstrip dipole antenna that can be mounted on metal object has been proposed. This tag antenna, which is composed of ladder feed line, rectangular loop, T-match and full ground plane, is easy to design and fabricate as the antenna structure does not contain any shorting plate or via hole between the patch and ground. The insertion of full ground plane in the tag antenna design reduces the negative impact of metal object to the performance of the tag antenna, thus make it suitable to be attached on metal object. The rest of the paper is conducted as follows: Section 2 describes the antenna design structure, Section 3 explains the simulation and the measurement result and finally conclusions and future works are summarized in Section 4.

\section{ANTENNA DESIGN STRUCTURE}

The proposed tag antenna design, which is called metal mountable ladder feed line tag antenna shows some improvement from the previous tag antenna design published in [9], in terms of size and gain, as a result of inserting a capacitive tip-loading structure and also the use of ladder feed line instead of a meander feed line respectively. The copper layer traces on the upper side of Rogers substrate formed several structures, including ladder feed line, rectangular loop, capacitive tip-loading and T-match as illustrated in Figure 1. The full ground plane at the back of the antenna will act as a reflector to the antenna and maintain the performance of the antenna even when attached on metal object. The Rogers substrate with the electric permittivity of 2.2 and a tangent loss of 0.0009 has a small thickness with only $0.8 \mathrm{~mm}$. At the center of the copper traces, a SOT1040 chip in form of strap from NXP Semiconductor with the impedance value of 14.8 $\mathrm{j} 127.1 \Omega$ is attached [10]. The overall dimension of the tag antenna is $53 \times 28 \times 0.8 \mathrm{~mm}^{3}$, which is $25 \%$ smaller than the tag antenna design in [9]. Table 1 shows the parameters and dimensions of the antenna structure.

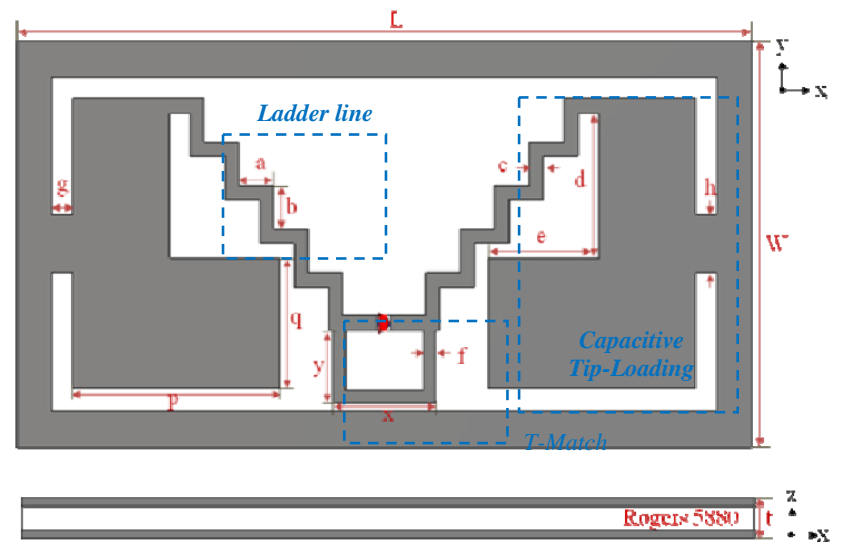

(a)

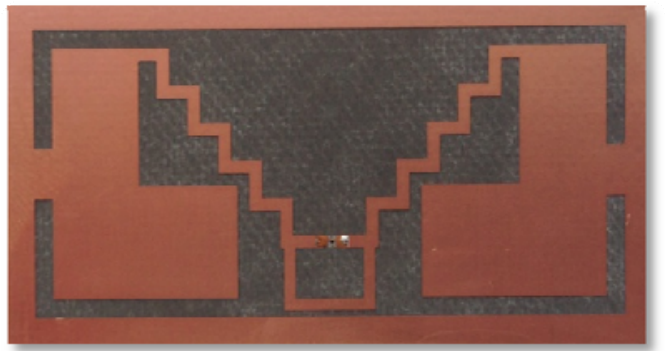

(b)

Figure 1. The (a) simulated and (b) fabricated proposed tag antenna structure

Table 1. Parameters and Dimension of Tag Antenna

\begin{tabular}{cccc}
\hline Parameter & Dimension $[\mathrm{mm}]$ & Parameter & Dimension $[\mathrm{mm}]$ \\
\hline $\mathrm{a}$ & 2 & $\mathrm{~h}$ & 4 \\
$\mathrm{~b}$ & 3 & $\mathrm{p}$ & 15 \\
$\mathrm{c}$ & 1 & $\mathrm{q}$ & 9 \\
$\mathrm{~d}$ & 10 & $\mathrm{x}$ & 7.4 \\
$\mathrm{e}$ & 8 & $\mathrm{y}$ & 5 \\
$\mathrm{f}$ & 0.9 & $\mathrm{~L}$ & 53 \\
$\mathrm{~g}$ & 1.5 & $\mathrm{~W}$ & 28 \\
\hline
\end{tabular}

The capacitive tip loading structure, which is a large radiating area at the end of the feeding line, is inserted in the tag antenna design to reduce the overall dimension of the antenna. Since most of the charges is stored at the end of the feed line dipole antenna, increasing the size of the structure near the ends will increase the capacitance of the antenna [11]. As a result, the resonant frequency will be shifted to the lower frequency. To increase the resonant frequency back near to the operating frequency, the size of the antenna 
will be reduced. Moreover, the added capacitance is roughly proportional to the perimeter of the loading shape [1]. Therefore, by using L-shaped of capacitive tip-loading structure, the perimeter of the loading shape can be more increased and varied, compared to the common rectangular shape, thus increase the capacitance of the antenna.

It is well known that small sized antenna will suffer a small antenna gain. But, other factor that can also affect the gain of the antenna besides the antenna size, is the mutual coupling that occurs between the meander line [12]. The currents that flow in the opposite direction in the meander line tends to cancel each other out as illustrated in Figure 2 (a) [1]. As a result, the antenna radiation resistance as well as the antenna efficiency will be decreased. Since the antenna efficiency is proportional to the antenna gain, decreasing the antenna efficiency will decrease the antenna gain. In order to reduce the current cancellation between the adjacent arms of the meander lines, the currents should be avoided to flow in the opposite direction. One of the solutions is by using ladder shape feed line instead of meander feed line as shown in Figure 2 (b). From the figure it can be seen, the current that flows in the opposite direction in the ladder line is brought further from each other. This will reduce the possibility of the current to be cancelled out. As a result, the antenna efficiency can be improved and the antenna gain will be increased, thus increase the tag read range as well.

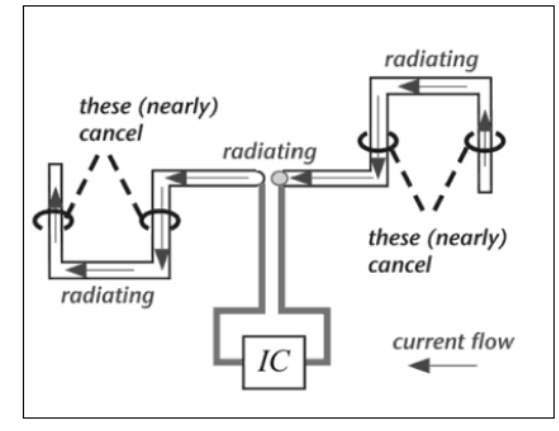

(a)

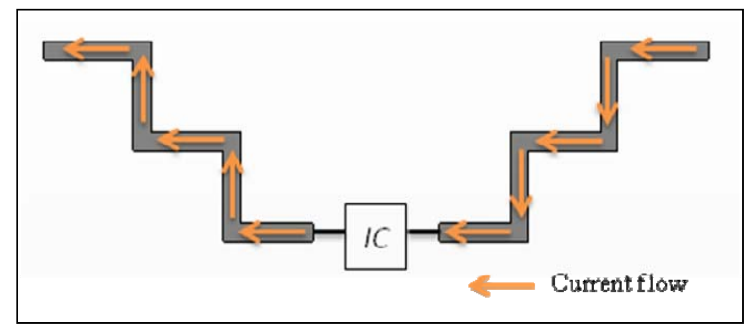

(b)

Figure 2. Current flow in the (a) meander feed line and (b) ladder feed line

The T-match structure is formed by connecting a short dipole indicated with parameter $\mathrm{x}$ and $\mathrm{y}$ to the ladder feed line to easily match the impedance of the antenna with the chip impedance without altering the whole dimension of the antenna. Since the impedance of the chip is highly capacitive, the antenna impedance needs to be highly inductive, so that maximum power will be transferred to the chip. The T-match structure is composed of a series and shunt inductance as illustrated in Figure 3. By altering the vertical and the horizontal length of the T-match, the value of the series and shunt inductance also will be changed. Therefore, the highly inductive antenna can be achieved only by altering the length of $\mathrm{x}$ and y parameters, while other parameters remain unchanged.

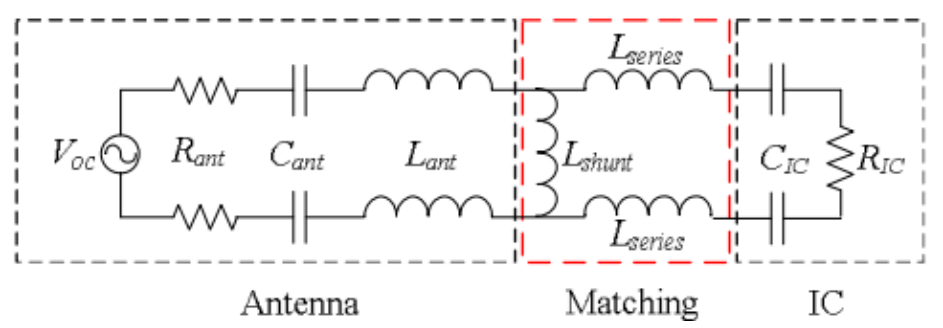

Figure 3. Tag antenna equivalent circuit with T-matching technique [1]

\section{SIMULATION AND MEASUREMENT RESULTS}

\subsection{Antenna Impedance}

The measurement of antenna impedance has been carried out using a method called Image Method [8], [13]. To utilize this Image Method, the antenna structure is divided symmetrically in half and mounted 
on a large electrical ground plane that includes the antenna feed point. Figure 4 (a) shows the measurement setup of the antenna impedance. The symmetric half tag antenna was mounted on a copper ground plane with the dimension of $30 \times 30 \mathrm{~cm}^{2}$. The antenna feeding point was soldered to the central pin of SMA connector at the back of the ground plane, which has been passed through a small hole in the copper plate. The metallic part of the antenna on the symmetric plane was also soldered to the ground plane. The SMA connector was connected to the Vector Network Analyzer (VNA) port through coaxial cable, which was hidden under the copper plate.

Figure 4 (b) shows the simulated and measured antenna impedance of the proposed tag antenna with respect to the frequency. From the graph, it can be seen that, at $921 \mathrm{MHz}$ the measured antenna impedance, $Z_{\text {meas }}=20.4+\mathrm{j} 290.5 \Omega$, is slightly higher than the simulated impedance with the value of $Z_{\text {sim }}=14.1+\mathrm{j} 126$ $\Omega$, especially in the reactance part. The increase of resistance and reactance of the measured antenna impedance is most probably due to the solder element that has been used to connect the antenna with the ground plane in the image method. The solder element acts as a parasitic element, which deteriorates the overall impedance of the antenna, thus increase the resistance as well as reactance of the antenna.

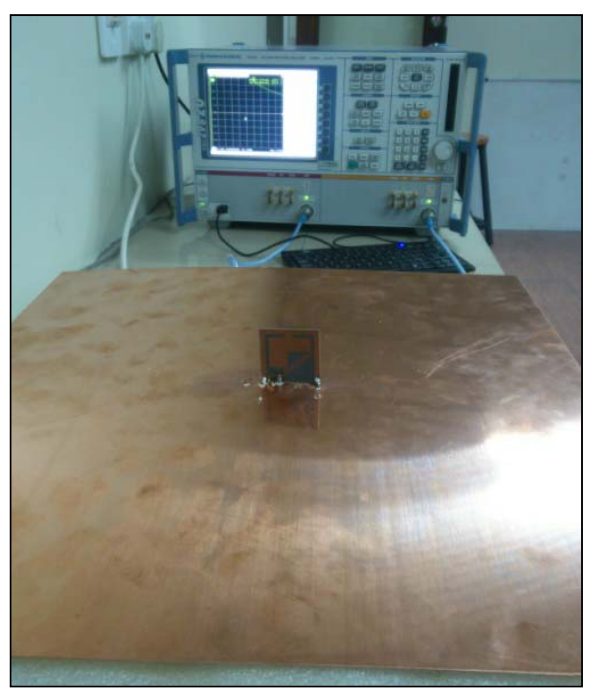

(a)

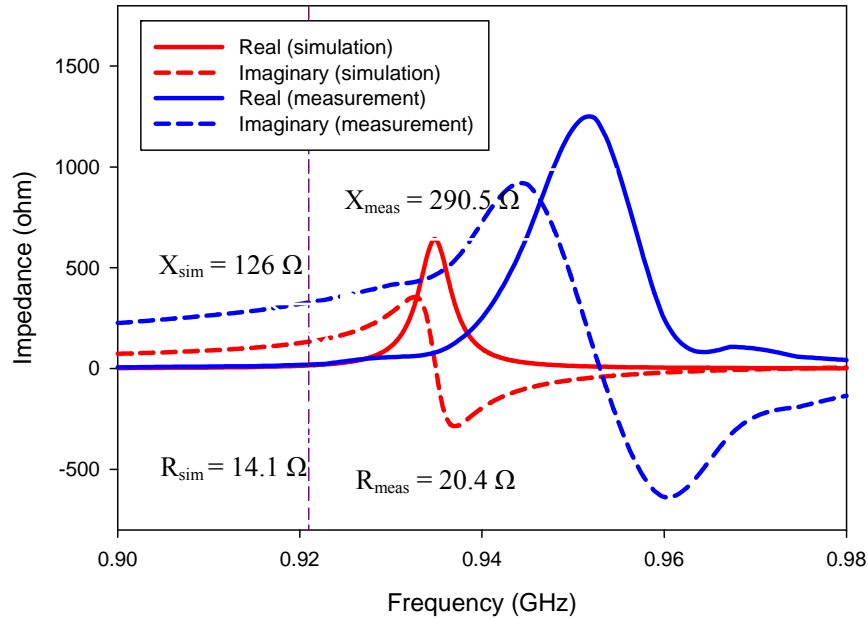

(b)

Figure 4. Antenna impedance (a) measurement setup (b) simulated and measured result

\subsection{Antenna Reflection Coefficient, $S_{11}$}

The measurement of $S_{11}$ was carried out using VNA from Rohde \& Shwarz and a jig. The jig, which used the concept of bazooka balun [14], was designed and simulated first to make sure that the jig was operated at the desired operating frequency, $921 \mathrm{MHz}$ as shown in Figure 5 (a). The fabricated jig shown in Figure 5 (b) was constructed using a $50 \Omega$ flexible RG316 coaxial cable shielded with Tan FEP jacket, SMA connector and a resistor with the impedance value of $15 \Omega$. The $15 \Omega$ load was inserted at the end of the jig in order to ensure that the output impedance of the jig is approximately the same as the chip impedance, which is $14.8 \Omega$. Figure 5 (c) shows the simulated and measured $S_{11}$ value of the jig. The simulated jig has wider bandwidth as compared to the fabricated jig. The slight difference in the $S_{11}$ value from the measured and simulated jig is due to the fabricated error of the jig and also the existence of parasitic element from the soldering process. Both the simulated and measured jigs cover the whole UHF range, which is $860-960$ $\mathrm{MHz}$ and the results agree well with each other.

The measurement setup of $S_{11}$ is shown in Figure 6 (a), where the prototype was connected to the jig at one end, followed by a coaxial cable to the VNA port at the other end. The antenna reflection coefficient was measured in two conditions, which are in free air and on copper plate with the dimension of $30 \mathrm{x} 30 \mathrm{~cm}^{2}$. It can be observed in Figure 6 (b) that the simulated as well as measured resonant frequency of the tag attached on metal is only slightly shifted from the simulated and measured tag in free air respectively. Thus, this result proved that this proposed tag antenna is suitable for metal object tagging, as the impedance of the antenna is not much affected when the tag is attached on metal. It can also be seen that the measured result is 
slightly shifted from the simulated results due to the fabricated error of the antenna and the jig as well as the existence of parasitic element from the soldering process. However, the resonant frequency is still acceptable as it is still within the UHF range.

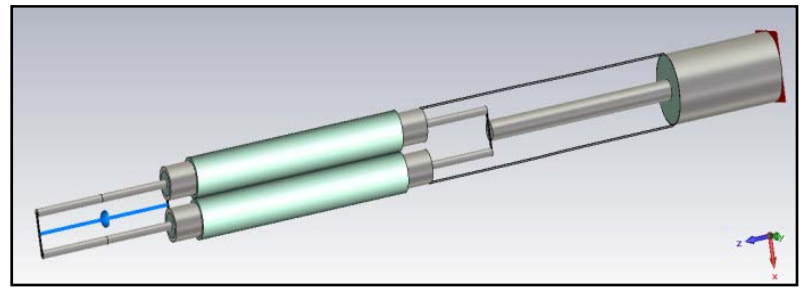

(a)

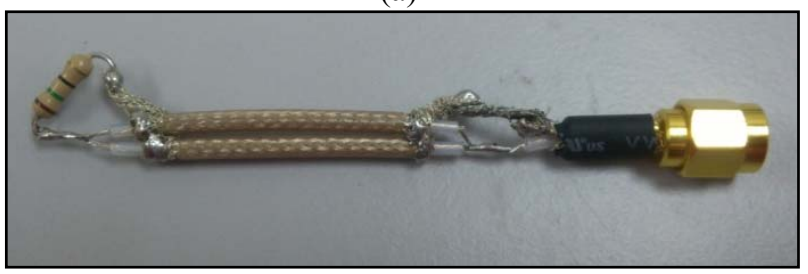

(b)

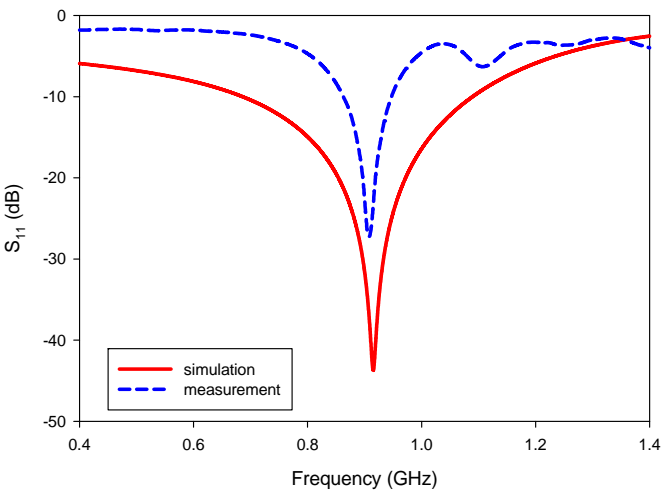

(c)

Figure 5. The (a) simulated and (b) fabricated jig and (c) the $S_{11}$ result of simulated and measured jig

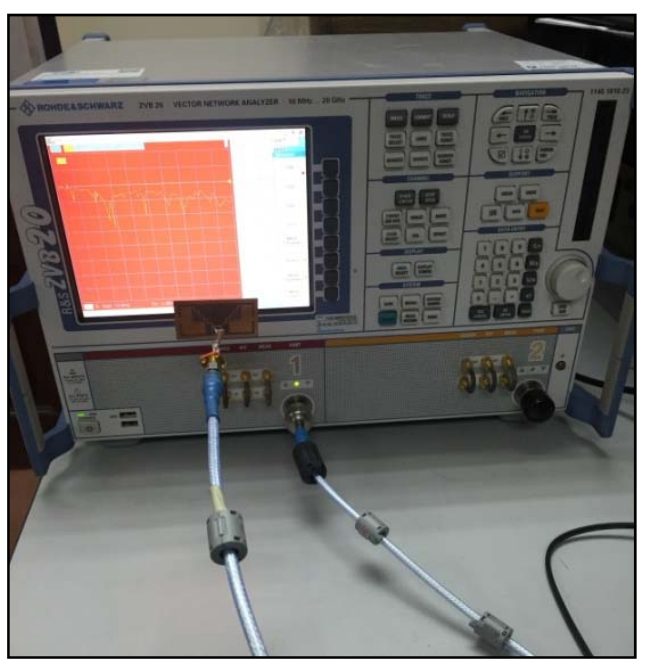

(a)

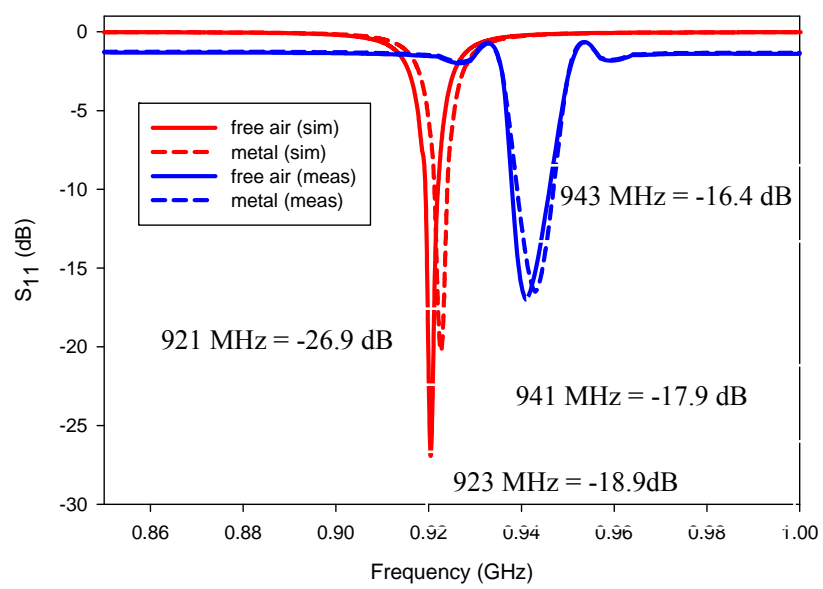

(b)

Figure 6. (a) The measurement setup of $\mathrm{S}_{11}$ and (b) simulated and measured $\mathrm{S}_{11}$ result

\subsection{Antenna Gain and Radiation Pattern}

Figure 7 (a) and (b) shows the simulated radiation pattern of the proposed tag antenna in polar plot when the tag is in free air and on metal object. In free air, there is radiation in backward direction because of the diffraction from the edge of the ground plane, which is also called edge effect [15]. However, when the tag is attached on metal object, the antenna radiation pattern becomes more directional as the metallic surface will reduce the field that diffracts from the edge of the ground plane, thus enhance the directivity of the tag antenna. At $921 \mathrm{MHz}$, the realized gain of the tag is $-8.97 \mathrm{~dB}$ and $-9.15 \mathrm{~dB}$ in free air and on metal respectively. The negative gain of the antenna is because of the small sized antenna, which is definitely smaller than a wavelength at the operating frequency $921 \mathrm{MHz}$. 


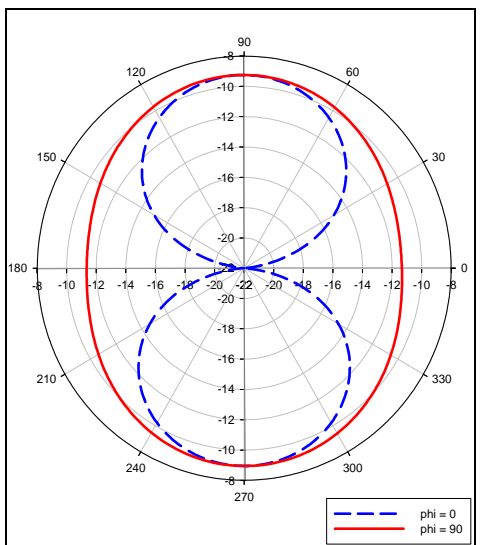

(a)

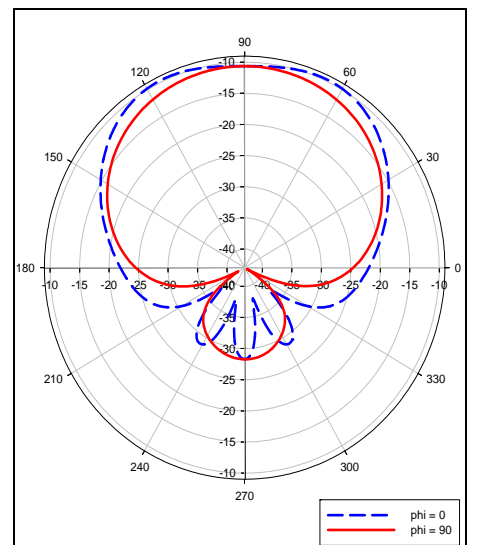

(b)

Figure 7. Polar radiation pattern of the proposed tag antenna in (a) free air and (b) on metal

Figure 8 shows the current distribution on the surface of the tag antenna. It can be seen that the current intensity is high at the ladder feed line and capacitive tip-loading structure. The current also distributed equally at the other radiating element including the rectangular loop. This agrees well with the theory of dipole, where the antenna radiation is maximum at the end of the dipole, which is at the ladder line and capacitive tip-loading, due to a large number of charges gathered there.

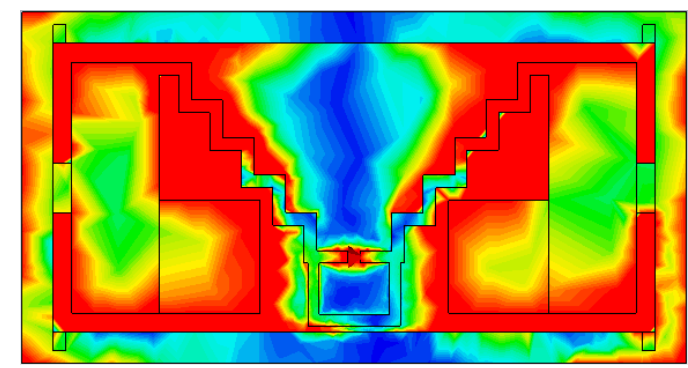

Figure 8. Current distribution on the surface of the tag antenna

\subsection{Read Range}

The tag reading range, which is the maximum distance that the reader can detect the tag, was measured using Evo-UHF2200 reader and type B circularly polarized antenna with the gain value of $9 \mathrm{dBi}$. The tag reading range can be calculated using the Friis equation in (1), where $P_{t}$ is the transmitted power from RFID reader, $\mathrm{G}_{\mathrm{r} / \mathrm{t}}$ is the gain from the reader and the tag, $\mathrm{P}_{\mathrm{th}}$ is the threshold power and $\tau$ is the power transfer coefficient [3] [16]. The power transfer coefficient, $\tau$ measures how much the antenna impedance is matched to the chip impedance and it can be calculated by using the equation in (2).

$$
\begin{gathered}
r=\frac{\lambda}{4 \pi} \sqrt{\frac{P_{t} G_{t} G_{r} \tau}{P_{t h}}} \\
\tau=\frac{4 R_{c} R_{a}}{\left|Z_{c}+Z_{a}\right|^{2}}
\end{gathered}
$$

From simulation, the maximum reading range obtained by the proposed tag antenna design is $3.2 \mathrm{~m}$ in free air and slightly lower on metal object with the distance of $3.1 \mathrm{~m}$ as shown in Figure 9 (a). The tag reading range obtained is $10 \%$ higher than the previous tag antenna design in [9] as a results of using ladder feed line instead of meander feed line in the tag antenna design. The measurement of the tag reading range 
was carried out in Antenne Research Group labarotory. Figure 9 (b) shows the setup for the tag reading range measurement. To measure the reading range, the tag was slowly moved away from the reader and the maximum distance that the reader can detect the tag was measured and recorded. The same procedure was repeated to verify the result. From measurement, the maximum reading range obtained when the tag was in free air is $2.3 \mathrm{~m}$, while on copper plate the reading range is around $2.2 \mathrm{~m}$. In comparison to the simulation result, the measured reading range has reduced around $0.9 \mathrm{~m}$ due to the inevitable interference from the surrounding.

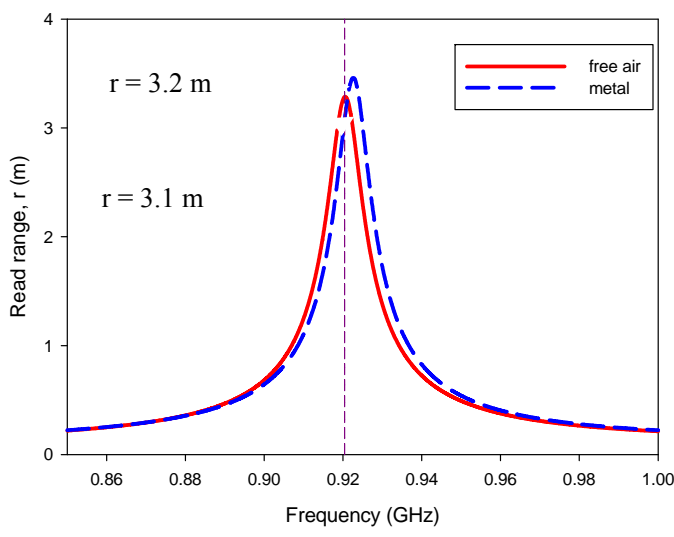

(a)

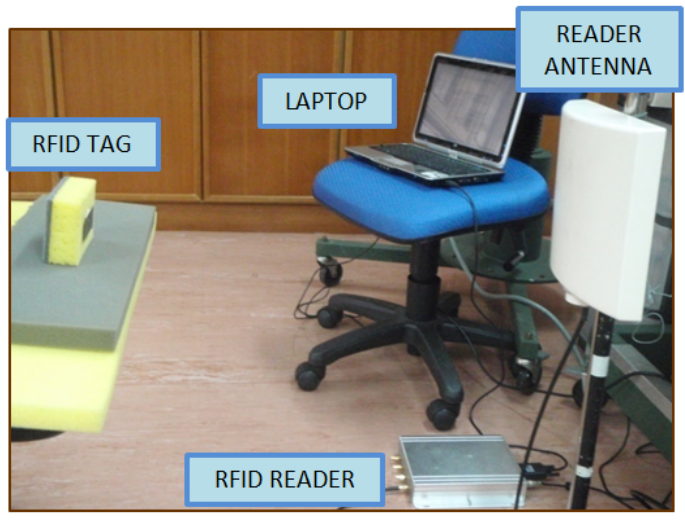

(b)

Figure 9. (a) Simulated reading range in free air and on metal (b) reading range measurement setup

\section{CONCLUSION}

Microstrip dipole UHF-RFID tag antenna, which can be mounted on metal object, has been proposed, designed and measured. The simple structure of the tag antenna without any shorting pin and via hole makes it easier to fabricate. The ladder feed line implemented in the tag antenna design has improved the gain of the antenna, meanwhile the capacitive tip loading structure contributes to the reduction of antenna size up to $25 \%$ from the previous design. Moreover, the existence of ground plane in the tag antenna design able to reduce the sensitivity of the tag to the metal object attached. As a result, the reader can detect the tag up to $2.2 \mathrm{~m}$ when attached on metal object. In the future, the measurement of tag reading range will be carried out outdoors in a large empty area to reduce the interference from the surrounding.

\section{ACKNOWLEDGEMENTS}

The authors would like to convey the deepest gratitude to Antenna Research Group (ARG), Microwave Technology Centre (MTC) and Universiti Teknologi Mara (UiTM) for support and guidance.

\section{REFERENCES}

[1] D.M. Dobkin, The RF in RFID: Passive UHF RFID in Practice. United States of America, 2008.

[2] A. Ferchichi, G. Ali, A. Info, S.R. Frequency, and A. Ferchichi, "A Novel Small Sierpenski Antennas", International Journal of Electrical and Computer Engineering (IJECE), vol. 3, no. 4, pp. 436-440, 2013.

[3] K.V.S. Rao, S. Member, P.V Nikitin, and S.F. Lam, "Antenna Design for UHF RFID Tags: A Review and a Practical Application”, IEEE Trans. Antennas Propag., vol. 53, no. 12, pp. 3870-3876, 2005.

[4] L. Mo and H. Zhang, "RFID Antenna Near the Surface of Metal", in International Symposium on Microwave, Antenna, Propagation and EMC Technologies for Wireless Communications, 2007, pp. 803-806.

[5] M. Bolic, D. Simplot-Ryl, and I. Stojmenovic, RFID Systems: Research Trends and Challenges. Wiley, 2010, p. 552.

[6] B. Gao and M.M.F. Yuen, "Passive UHF RFID with Ferrite Electromagnetic Band Gap ( EBG ) Material for Metal Objects Tracking Capacitor Capacitor a", in Electronic Components and Technology Conference, 2008, pp. 19901994.

[7] M. Abu and M.K.A. Rahim, "Single-band and Dual-band Artificial Magnetic Conductor Ground Planes for Multiband Dipole Antenna", vol. 21, no. 4, pp. 999-1006, 2012. 
[8] H.G. Cho, N.R. Labadie, and S.K. Sharma, "Design of an embedded-feed type microstrip patch antenna for UHF radio frequency identification tag on metallic objects", IET Microwaves, Antennas Propag., vol. 4, no. 9, p. 1232, 2010.

[9] N.M. Faudzi, M.T. Ali, I. Ismail, H. Jumaat, and N.H.M. Sukaimi, "Metal Mountable UHF-RFID Tag Antenna with Meander Feed Line and Double T-Match", in International Symposium on Technology Management and Emerging Technologies, 2014.

[10] NXP Semiconductor, "Product Data Sheet SL3ICS1002/1202 UCODE G2XM and G2XL", 2012.

[11] T. Hu and C. Liu, "Design and Analysis of UHF Tag Antenna Structure", China-Japan Jt. Microw. Conf. Proc., pp. $1-4,2011$.

[12] B.M. Iravani, "Electromagnetic Interference Reduction using EBG structures in Packages, Enclosures, Cavities and Antennas", University of Maryland, College Park, 2007.

[13] Y. Tikhov, Y. Kim, and Y. Min, "Compact Low Cost Antenna for Passive RFID Transponder", in IEEE Antennas and Propagation Society International Symposium, 2009, pp. 1015-1018.

[14] H. Arai, "Antenna Measurements for Radio Handsets and Mobile Terminals", in Measurement of Mobile Antenna Systems, Second., Artech House, 2013, p. 230.

[15] M.F. Otero and R.G. Rojas, "Analysis and Treatment of Edge Effects on the Radiation Pattern of a Microstrip Patch Antennat", in Antennas and Propagation Society International Symposium, 1995, pp. 1050-1053.

[16] T.A. Rahman, S. Kamal, A. Rahim, S.L. Rosa, and E.P.C. Gen, "Development of RFID EPC Gen2 Tag for Multi Access Control System", International Journal of Electrical and Computer Engineering (IJECE), vol. 3, no. 6, pp. 724-731, 2013.

\section{BIOGRAPHIES OF AUTHORS}

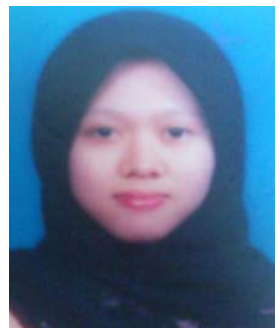

Najwa Mohd Faudzi was born in Kelantan, Malaysia. She received the B.Sc degree in Electrical Engineering from Hochschule Osnabrueck, Germany in 2012. Currently she furthers her study in M.Sc in Electrical Engineering at Universiti Teknologi Mara (UiTM), Shah Alam, Malaysia since 2012. Her research interests include RFID system, radio wave propagation and antennas. She is a member of IEEE and now attached with Antenna Research Group (ARG), UiTM.

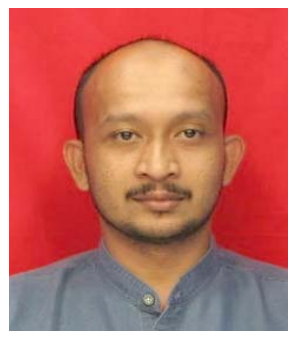

Dr. Mohd Tarmizi Ali received the B. Eng. Degree in electrical engineering from Universiti Teknologi Mara (UiTM), Selangor, Malaysia in 1996 and the M. Sc. degree in electrical engineering from University of Leeds, United Kingdom, in 2002. He received the Ph.D degree in electrical engineering from Universiti Teknologi Malaysia (UTM), Johor, Malaysia in 2010. He has published over 100 journal papers and conferences proceeding on various topics related to antennas, microwaves and electromagnetic radiation analysis. He also has filled 5 patent applications on communication antennas. Thus far, his publications have been cited 237 times, and the H-index is 8 (Source: Google Scholar). His professorial interests include the areas of communication antenna design, radio astronomy antennas, satellite antennas, and electromagnetic radiation analysis.

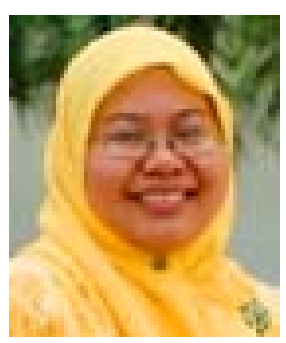

Ismarani Ismail received the B Eng. Degree in Electrical and Electronics Engineering from John Moores University, Liverpool, UK. is a Senior lecturer at the Faculty of Electrical and Ph. $\mathrm{D}$ in Electronics Manufacturing Engineering from University of Salford, UK. Her main research interest is in RFID system, electronics product and system development, electronic and electrical manufacturing processes. She has published in a number of national and international journals. 


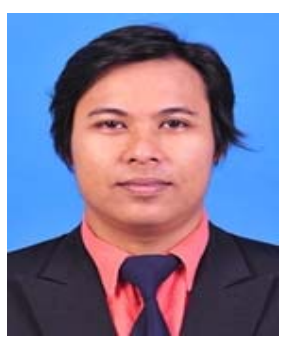

Hadi Jumaat was born in Johor, Malaysia. He completed his Diploma study in Mara Poly-Tech College, Kuantan, Malaysia in 2009. Later, he received the B.Sc degree in Electronics Engineering from Universiti Teknologi Mara (UiTM), Shah Alam, Malaysia in 2012. He is currently further his study in M.Sc Electrical Engineering at UiTM, Shah Alam, Malaysia since 2012. His research interests include plasma antennas, LTCC and microwave technologies. He is a member of IEEE Malaysia and now attached with Antenna Research Group (ARG) in UiTM, Malaysia.

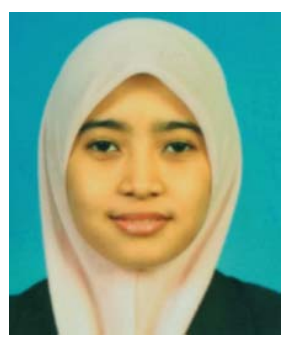

Nur Hidayah Mohd Sukaimi was born in Johor Bahru, Malaysia. She completed her Diploma study in Universiti Teknologi Mara (UiTM), Penang, Malaysia in 2009. Later, she received the B.Sc degree in Electrical Engineering from UiTM, Shah Alam in 2012. Currently she furthers her study in M.Sc Electrical Engineering in UiTM, Shah Alam, since 2012. Her research interests include LTCC, microwave and antennas. She is a member of IEEE Malaysia and now attached with Antenna Research Group (ARG), in UiTM, Malaysia. 